\title{
Caracterização morfológica, determinação do número de embriões e taxa de poliembrionia em três porta-enxertos híbridos de citros
}

\author{
Divanilde Guerra ('); Maria Teresa Schifino-Wittmann (2*); Sergio Francisco Schwarz (1); Paulo Vitor \\ Dutra de Souza ( $\left.{ }^{1}\right)$; Roberto Luis Weiler $\left(^{2}\right)$ \\ (') Universidade Federal do Rio Grande do Sul (UFRGS), Faculdade de Agronomia, Departamento de Horticultura e Silvicultura, Caixa \\ Postal 15100, 91501-970 Porto Alegre (RS), Brasil. \\ (2) UFRGS, Departamento de Plantas Forrageiras e Agrometeorologia, 91501-970 Porto Alegre (RS), Brasil. \\ $\left.{ }^{*}\right)$ Autora correspondente: mtschif@ufrgs.br
}

Recebido: 19/jan./2012; Aceito: 3/maio/2012

\section{Resumo}

Tendo em vista inúmeros problemas fitossanitários que vêm acometendo a citricultura brasileira, a diversificação de porta-enxertos é uma necessidade prioritária. Híbridos de porta-enxertos estão sendo desenvolvidos por programas de melhoramento genético de citros, os quais devem ser avaliados quanto a características morfológicas e de produção. Por esse motivo, o objetivo deste trabalho foi caracterizar folhas e frutos, determinar o número de embriões por semente e avaliar a taxa de poliembrionia de três porta-enxertos híbridos: citranges ‘Fepagro C 13', 'Fepagro C 37’ e 'Fepagro C 41' e compará-los a três porta-enxertos já utilizados na sustentação dos pomares de citros: Trifoliata, citrumelo 'Swingle' e citrange 'Troyer'. Pouca variação foi observada na caracterização morfológica das folhas, porém na caracterização dos frutos foram verificadas diferenças. Destacam-se os citranges 'Fepagro C 13' e 'Fepagro C 37’ que produziram, na média, muitas sementes por fruto, ou seja, 24,2 e 35,0, sendo muitas viáveis, 19,2 e 21,2 e estas portando bom número de embriões, 5,0 e 3,1, além de altas taxas de poliembrionia, 84 e 92\% respectivamente. Os resultados obtidos com os dois híbridos demonstram que eles possuem bom potencial para serem utilizados como plantas doadoras de sementes para porta-enxertos de citros.

Palavras-chave: citricultura, porta-enxertos alternativos, morfologia de folhas e frutos.

\section{Morphological characterization, embryo number determination and polyembriony taxes in three citrus hybrid rootstocks}

\begin{abstract}
Due to several phytosanitary problems that affect Brazilian citriculture, diversification of rootstocks is a priority. Hybrid root-stocks are being developed by citrus genetic breeding programs, and those hybrids must be evaluated regarding morphological characteristics and yield. Therefore, the objective of the present paper was to characterize leaves and fruits, to determine embryo number per seed and to evaluate polyembriony rates of three hybrid rootstocks: citranges 'Fepagro C 13', 'Fepagro C 37' and 'Fepagro C 41', comparing then to three other rootstocks currently used in citrus orchards Trifoliata, citrumelo 'Swingle' and citrange 'Troyer'. Little morphological variation was found in leaves but, for fruits, some differences were observed, especially in citranges 'Fepagro C 13' and 'Fepagro C 37' that produced, in average, many seeds per fruit 24.2 and 35.0, many of them viable, 19.2 and 21.2 and with a good number of embryos 5.0 and 3.1, respectively, besides presenting high polyembriony taxes, $84 \%$ and $92 \%$, respectively. The results show that these two hybrids have a good potential to be used as seed donor plants to citrus rootstocks.
\end{abstract}

Key words: citriculture, alternative rootstocks, leaves and fruits morphology.

\section{INTRODUÇÃO}

Em citros, o porta-enxerto exerce muitas influências sobre a planta e os frutos podendo afetar mais de 20 características, dentre elas, o desenvolvimento da cultivar-copa, teor de nutrientes das folhas, produção e tamanho dos frutos, quantidade de suco, teor de sólidos solúveis totais, acidez do suco
(SchäFER et al., 2001), além de tolerância a problemas fitossanitários (Chagas et al., 2007). Por esse motivo, a escolha da cultivar a ser utilizada é uma fase muito importante no planejamento do pomar, devendo ser levadas em consideração características de clima, solo, variedade-copa, manejo (SCHÄFER et al., 2001), bem como as moléstias que acometem a cultura na regiáo (PAssos et al., 2006). 
A diversidade de gêneros, espécies e cultivares é muito grande em citros; no entanto, um número relativamente pequeno de porta-enxertos é utilizado nos plantios comerciais, devido a razóes botânicas e históricas (Mourấo Filho et al., 2008). A não diversificação de porta-enxertos torna a citricultura brasileira vulnerável ao surgimento de novas moléstias e coloca em risco sua continuidade. Além disso, a utilização generalizada de um mesmo porta-enxerto para todas as cultivares-copas, provavelmente náo atende às características peculiares de cada variedade, impedindo que a planta, mesmo recebendo os tratos culturais adequados, manifeste todo o seu potencial produtivo (Pompeu Junior et al., 2002). Portanto, a diversificação de porta-enxertos é uma necessidade prioritária para garantir o sucesso da atividade citrícola nas próximas décadas.

As novas seleçóes de porta-enxertos devem conferir produtividade e qualidade aos frutos da cultivar-copa, ser tolerantes às principais pragas e doenças da cultura $\mathrm{e}$ devem induzir redução do tamanho da planta (Pompeu Junior e Blumer, 2009). Além disso, devem produzir muitos frutos, com grande número de sementes e estas com alta poliembrionia nucelar. De acordo com Passos et al. (2006), quanto mais elevada a taxa de poliembrionia nas sementes, maiores são as chances de o porta-enxerto, quando propagado, resultar em plântulas de origem nucelar, semelhantes à cultivar-mãe, garantindo assim a mesma constituição genética e favorecendo a homogeneidade dos pomares.

O objetivo deste estudo foi caracterizar morfologicamente folhas e frutos, determinar o número de embriōes por semente pelos métodos direto e indireto e avaliar a taxa de poliembrionia de três porta-enxertos e compará-los a três porta-enxertos já utilizados na citricultura.

\section{MATERIAL E MÉTODOS}

Para a realização dos experimentos foram utilizados folhas e frutos dos porta-enxertos Trifoliata (Poncirus trifoliata (L.) Raf,), citrumelo 'Swingle' (Citrus paradisi Macf. x P. trifoliata), citrange 'Troyer' (C. sinensis Osb. $\mathrm{x} P$. trifoliata) e de três citranges desenvolvidos pela FEPAGRO (Fundação Estadual de Pesquisa Agropecuária, RS), denominados 'Fepagro C 13', 'Fepagro C 37' e 'Fepagro C 41', resultantes de hibridaçôes realizadas na entâo Estação Experimental Fitotécnica de Taquari (RS), em 1956, por Carlos Modesto Motta Dornelles (Souza e Lobato, 2010). Todos tiveram como genitor feminino a laranja 'Pera' $(C$. sinensis) e genitor masculino o $P$. trifoliata. As plantas estão enxertadas sobre citrumeleiro 'Swingle' e foram plantadas em campo em 1996, sem irrigação, na Fazenda Panoramas Citros, localizada no Município de Butiá (RS), com latitude de $29^{\circ} 57^{\prime}$ S e longitude de 51²0’W.
Para a análise morfológica, foram coletadas 20 folhas completamente desenvolvidas de cada um dos porta-enxertos, sendo cinco em cada quadrante, as quais foram analisadas e classificadas quanto ao tipo, à cor, ao comprimento do pecíolo em relação ao limbo, pecíolo alado, à forma do pecíolo, forma do limbo e ao formato da margem, conforme descrição do IBPGR (1988). Com um paquímetro foram feitas as mediçóes das folhas, sendo mensurado o comprimento do pecíolo, a largura (feita no ponto mais largo da lâmina foliar) e o comprimento da folha, bem como o comprimento total (limbo mais pecíolo). Como as folhas são trifolioladas, as análises foram realizadas no folíolo central.

Dez frutos de cada um dos materiais, coletados cinco em cada lado da linha de plantas, foram colhidos quando estavam visualmente em fase de maturação. Os parâmetros avaliados foram: forma, formato da base e formato do ápice, de acordo com o descrito no IBPGR (1988). Com um paquímetro foram feitas as mediçôes do diâmetro e da altura dos frutos e em balança de precisão foi mensurada a massa. Procedeu-se a abertura transversal com um bisturi, fêz-se a extração individual de todas as sementes, contadas e classificadas em viáveis (cheias) ou inviáveis. Foram consideradas sementes inviáveis, vazias ou não desenvolvidas, aquelas sem embriáo no seu interior ou com embriáo morto ou sementes de desenvolvimento insuficiente, de tamanho muito pequeno, mas ainda visível.

A determinação do número médio de embrióes por semente foi efetuada através do exame de 200 sementes de cada um dos porta-enxertos. Pelo método direto, com o auxílio de pinça e bisturi e sob lupa, a casca e o tegmento de 100 sementes/porta-enxerto foram retirados e procedeu-se a separação e a contagem dos embriôes. Pelo método indireto, cem sementes de cada porta-enxerto foram selecionadas e submetidas a um processo de escarificaçáo, utilizando-se o tratamento químico de referência (TQR) descrito por Oliveira et al. (2006), no qual as sementes foram imersas, sob agitação por 45 minutos, em solução contendo 0,5 litro de hipoclorito de sódio $(\mathrm{NaClO})$ a $12 \%, 3 \mathrm{~mL}$ de ácido clorídrico ( $\mathrm{HCl}$ ) e $20 \mathrm{~g}$ de hidróxido de sódio comercial $(\mathrm{NaOH})$, dissolvidos em um litro de água. Após a agitação, as sementes foram lavadas com água corrente e procedeu-se a remoção do tegumento externo esfregando-se as sementes umas sobre as outras, no interior de um pano úmido. Após a escarificação, as sementes foram postas a germinar em bandejas de germinação (uma semente por alvéolo) preenchidas com substrato comercial para citros da marca comercial Rendmax. O delineamento experimental foi completamente casualizado, e quatro repetiçóes com 25 sementes compunham cada tratamento. As bandejas foram mantidas em casa de vegetação por 60 dias e após este período, as plântulas foram retiradas dos alvéolos, separadas e contadas.

Os resultados da caracterização morfológica das folhas e dos frutos, da determinação do número de embriōes 
por semente e da taxa de poliembrionia foram analisados pelo teste de Tukey a $5 \%$ de probabilidade, utilizando o programa estatístico SAS.

\section{RESULTADOS E DISCUSSÃO}

$\mathrm{Na}$ caracterização morfológica das folhas, em todas as plantas avaliadas havia folhas do tipo dois, conforme a classificação sugerida pelo IBPGR (1988), ou seja, trifolioladas. Os materiais utilizados no estudo foram o Trifoliata e híbridos obtidos através do cruzamento com outros genótipos. Por esse motivo, a presença de folhas trifolioladas era esperada, pois esta característica é governada por um gene dominante (CAMEron e Frost, 1968; Garcia et al., 1999).

Quanto à cor, comprimento do pecíolo em relação ao limbo, pecíolo alado, forma do pecíolo e formato da margem, todos os materiais tiveram as mesmas características. Porém para a forma do limbo, no porta-enxerto Trifoliata observou-se forma orbiculada, enquanto nos demais a forma era elipsoide (Tabela 1). Com relação às médias das características: largura, comprimento do limbo e comprimento total das folhas foram observadas variaçóes entre os genótipos. Na largura, o menor valor foi de $2,6 \mathrm{~cm}$ em Trifoliata e o maior de 4,1 cm em 'Fepagro C 37'. No comprimento, o menor valor foi de 5,6 cm em Trifoliata e o maior de $8,6 \mathrm{~cm}$ em 'Swingle' e no comprimento total, o menor valor foi de 7,0 cm em Trifoliata e o maior de 10,7 cm em 'Swingle' (Tabela 2). Na comparação entre os citranges 'Fepagro C 13', 'Fepagro C 37' e 'Fepagro C 41' com o Trifoliata, observaram-se nos citranges valores superiores a este em largura, comprimento do limbo e comprimento total das folhas, características herdadas, possivelmente do genitor feminino C. sinensis (Tabela 2).

A caracterização morfológica, através de descritores botânicos herdáveis, facilmente visíveis e mensuráveis, que a princípio são expressos em todos os ambientes representa uma importante ferramenta para a distinção dos genótipos (IBPGR, 1988). Porém em plantas com alta semelhança fenotípica, como neste estudo, a caracterização por esta técnica pode ser dificultada. Concordando com o que é relatado por BaLlvé et al. (1997) que salientam a dificuldade na diferenciação de plantas cítricas muito similares através de marcadores morfológicos. Contudo bons resultados foram obtidos na caracterizaçáo morfológica por Koenler-Santos et al. (2003) em 34 variedades de tangerineiras e por WeILER et al. (2011) em uma progênie obtida pelo cruzamento das tangerinas 'Clementina Fina' (C. clementina Hort. ex Tan.) x 'Montenegrina' (C. deliciosa Ten.).

$\mathrm{Na}$ caracterizaçáo morfológica dos frutos, foram observadas variaçôes entre porta-enxertos (Tabelas 3 e 4). Não houve variaçáo quanto ao formato do ápice, sendo os frutos de todos os genótipos classificados como convexo (Tabela 3), porém para a característica forma, os frutos do citrumelo 'Swingle' foram classificados como periniforme, enquanto os frutos dos demais, como esferoides (Tabela 3). No formato da base novamente nos frutos do citrumelo 'Swingle' houve diferença em relação aos demais genótipos, sendo classificado como de formato da base com pescoço, enquanto os demais eram convexos (Tabela 3). A diferença na forma e no formato da base dos frutos deve estar associada à distinta constituição genética

Tabela 2. Caracterização morfológica das folhas de plantas matrizes dos porta-enxertos de citros desenvolvidos em campo, Butiá (RS)

\begin{tabular}{lccc} 
Planta & $\begin{array}{c}\text { Largura } \\
\text { folha } \\
\text { (cm) }\end{array}$ & $\begin{array}{c}\text { Comprimento } \\
\text { folha (cm) }\end{array}$ & $\begin{array}{c}\text { Comprimento total } \\
\text { (Limbo + pecíolo) } \\
\text { (cm) }\end{array}$ \\
\hline Trifoliata & $2,6 \mathrm{~d}$ & $5,6 \mathrm{~d}$ & $7,0 \mathrm{~d}$ \\
'Swingle' & $3,8 \mathrm{C}$ & $8,6 \mathrm{a}$ & $10,7 \mathrm{a}$ \\
'Troyer' & $3,7 \mathrm{c}$ & $6,4 \mathrm{c}$ & $8,4 \mathrm{C}$ \\
'Fepagro C 13' & $3,9 \mathrm{~b}$ & $6,7 \mathrm{c}$ & $8,6 \mathrm{C}$ \\
'Fepagro C 37' & $4,1 \mathrm{a}$ & $7,4 \mathrm{~b}$ & $9,5 \mathrm{~b}$ \\
'Fepagro C 41' & $3,9 \mathrm{~b}$ & $7,3 \mathrm{~b}$ & $9,2 \mathrm{~b}$
\end{tabular}

Médias seguidas de mesma letra minúscula na coluna não diferem significativamente pelo teste de Tukey $(\mathrm{p}>0,05)$.

Tabela 3. Caracterização morfológica dos frutos de plantas matrizes dos porta-enxertos de citros desenvolvidos em campo, Butiá (RS)

\begin{tabular}{lccc} 
Planta & Forma & Formato da base & $\begin{array}{c}\text { Formato do } \\
\text { ápice }\end{array}$ \\
\hline Trifoliata & Esferoide & Convexo & Convexo \\
'Swingle' & Periniforme & Com pescoço & Convexo \\
'Troyer' & Esferoide & Convexo & Convexo \\
'Fepagro C 13' & Esferoide & Convexo & Convexo \\
'Fepagro C 37' & Esferoide & Convexo & Convexo \\
'Fepagro C 41' & Esferoide & Convexo & Convexo
\end{tabular}

Tabela 1. Caracterização morfológica das folhas de plantas matrizes dos porta-enxertos de citros desenvolvidos em campo, Butiá (RS)

\begin{tabular}{|c|c|c|c|c|c|c|}
\hline Planta & Cor & $\begin{array}{c}\text { Pecíolo } \\
x \\
\text { Limbo }\end{array}$ & Pecíolo alado & Forma pecíolo & Forma limbo & $\begin{array}{l}\text { Formato } \\
\text { margem }\end{array}$ \\
\hline Trifoliata & verde & Brevip. & estreito & obovado & orbiculada & dentada \\
\hline 'Swingle' & verde & Brevip. & estreito & obovado & elipsoide & dentada \\
\hline ‘Troyer’ & verde & Brevip. & estreito & obovado & elipsoide & dentada \\
\hline ‘Fepagro C13’ & verde & Brevip. & estreito & obovado & elipsoide & dentada \\
\hline 'Fepagro C 41’ & verde & Brevip. & estreito & obovado & elipsoide & dentada \\
\hline
\end{tabular}

Brevip. $=$ brevipecioladas 
dos genótipos, concordando com STUCHI et al. (1996) e SoAres Filho et al. (2000), que atribuem as diferenças na morfologia do fruto, no número total de sementes e na porcentagem de sementes viáveis em citros a fatores genéticos e ambientais, hipótese também sugerida por Domingues et al. (1999) para as diferenças morfológicas dos frutos em dez variedades de tangerineiras.

Foi observada variação nas características diâmetro, altura e massa. Entre os porta-enxertos já utilizados, o citrumelo 'Swingle' proporcionou os maiores valores com $6,5 \mathrm{~cm}$ de diâmetro, $6,6 \mathrm{~cm}$ de altura e 85,6 g de massa; nos citranges, os maiores valores foram observados em 'Fepagro C 41', com 6,1 cm, 6,5 cm e 116,9 g respectivamente (Tabela 4). No presente trabalho, os valores de altura, diâmetro, massa e número de sementes em Trifoliata, citrumelo 'Swingle' e citrange 'Troyer' (Tabela 4) foram superiores aos obtidos por PAssos et al. (2006), que obtiveram em uma seleção de Trifoliata valores de $3,6 \mathrm{~cm}, 4,1$ cm, 31,2 g e 8,7 respectivamente; em citrumelo 'Swingle' valores de $5,2 \mathrm{~cm}, 5,3 \mathrm{~cm}, 71,1 \mathrm{~g}$ e 24,7 respectivamente e em citrange 'Troyer' valores de 4,4 cm, 4,7 cm, 53,0 g e 13,2 respectivamente. Ramos et al. (2006) obtiveram, em uma seleção de Trifoliata, 28,9 sementes/fruto, sendo 26,6 viáveis, valores inferiores aos obtidos neste trabalho com 39,6 sementes/fruto e 38,2 viáveis. Estas diferenças podem estar associadas ao manejo, a fatores ambientais e à possível diversidade de seleção da espécie.

Um caractere importante na seleção de novos porta-enxertos é a quantidade de sementes produzidas por fruto e sua viabilidade. Neste estudo, o maior número e a viabilidade foram observados em Trifoliata, com total de 39,6 sementes/fruto e 38,2 viáveis (Tabela 4), sendo esta uma das características que faz deste porta-enxerto um dos mais utilizados na sustentação dos pomares de citros no Rio Grande do Sul. Na comparação com o Trifolita, nos novos porta-enxertos observaram-se valores inferiores, mas mesmo assim, os valores totais e de viabilidade são adequados; os híbridos 'Fepagro C 13', 'Fepagro C 37' e 'Fepagro C 41' produziram, respectivamente, 24,2, 35,0 e 20,4 sementes/fruto, porém, com alta viabilidade, com valores de 19,2, 21,2 e 16,8 respectivamente, característica muito importante, demonstrando que neste quesito, há grande potencial no uso como porta-enxertos (Tabela 4). O número total de sementes e a viabilidade parece ser um fator genético, mas com alta influência do ambiente e do sistema de manejo utilizado, pois, neste estudo, a média do número de sementes para os citranges 'Troyer' e 'Fepagro C 13' e citrumelo 'Swingle' foi de 30,6, 24,2 e 38,8 respectivamente (Tabela 4), valores superiores aos descritos por Koller (1994), para estes porta-enxertos, de 15,15 e 18 sementes/fruto respectivamente. Neste estudo, em citrumelo 'Swingle' foram obtidas 38,8 sementes, sendo 23,2 viáveis, porém Moreira et al. (2010) observaram valores superiores de sementes/ fruto com valor de 58,0 e viabilidade de 26,0.

Variações no número de embriôes, pelo método direto e indireto, foram observadas nos genótipos avaliados (Tabela 4). Pelo método direto, o maior número de embrióes/semente foi observado em 'Fepagro C 13', com 5,0 embrióes/semente e o menor valor de 2,0 embriôes/semente em citrumelo 'Swingle'. Pelo método indireto, o maior número de plantas germinadas por semente foi de 3,1 em citrumelo 'Swingle' e o menor de 1,2 em 'Fepagro C 41' (Tabela 4). As diferenças devem estar associadas a inúmeros fatores, o que concordaria com Garcia et al. (1999), de que a proporção de embrióes nucelares parece variar entre as espécies cítricas; fatores ambientais, nutrição da planta, cultivar, forma de polinização e variedade polinizadora atuam diretamente no tamanho e no número de embrióes contidos em uma semente, além de poder ocorrer variaçôes em frutos da mesma planta no mesmo ano e entre as plantas em anos distintos (Moreira et al., 2010). Fatores ambientais são relatados como os responsáveis por variaçôes no número de embriôes por semente por Soares Filho et al. (2000), em tangerina 'Clementina' (C. clementina), tangerina 'Sunki' (C. sunki Hort. ex. Tan.), limão 'Cravo' (C. limonia Osbeck) e limão 'Volkameriano' ( $C$. volkameriana Tem \& Pasq.) e por Aleza et al. (2011) em diversas variedades de tangerineiras.

O 'Fepagro C13' foi registrado no Registro Nacional de Cultivares (RNC) do Ministério da Agricultura, Pecuária e Abastecimento (MAPA), em 2007, como 'Fepagro C 13' (Souza e Lobato, 2010). Este porta-enxerto tem se destacado como promissor, nos estudos em campo, com

Tabela 4. Valores médios da caracterização dos frutos de plantas matrizes dos porta-enxertos de citros desenvolvidos em campo, Butiá (RS)

\begin{tabular}{lccccccccc} 
Porta-enxerto & $\begin{array}{c}\text { Diâmetro } \\
(\mathbf{c m})\end{array}$ & $\begin{array}{c}\text { Altura } \\
\text { (cm) }\end{array}$ & $\begin{array}{c}\text { Massa } \\
\text { (g) }\end{array}$ & $\begin{array}{c}\text { Sementes } \\
\text { (unid.) }\end{array}$ & $\begin{array}{c}\text { Sementes } \\
\text { Viáveis } \\
\text { (unid.) }\end{array}$ & $\begin{array}{c}\text { Sementes } \\
\text { Inviáveis } \\
\text { (unid.) }\end{array}$ & $\begin{array}{c}\text { Embriões } \\
\text { (unid.) }\end{array}$ & $\begin{array}{c}\text { Germinação } \\
\text { Substrato } \\
\text { (?) }\end{array}$ & $\begin{array}{c}\text { Poliembrionia } \\
\text { (\%) }\end{array}$ \\
\hline Trifoliata & $4,7 \mathrm{c}$ & $4,7 \mathrm{c}$ & $38,5 \mathrm{~d}$ & $39,6 \mathrm{a}$ & $38,2 \mathrm{a}$ & $1,6 \mathrm{c}$ & $2,3 \mathrm{c}$ & $1,9 \mathrm{c}$ & 52 \\
'Swingle' & $6,5 \mathrm{a}$ & $6,6 \mathrm{a}$ & $85,6 \mathrm{~b}$ & $38,8 \mathrm{a}$ & $23,2 \mathrm{~b}$ & $15,6 \mathrm{a}$ & $2,0 \mathrm{c}$ & $3,1 \mathrm{a}$ & 94 \\
\hline 'Troyer' & $5,3 \mathrm{~b}$ & $5,4 \mathrm{~b}$ & $53,1 \mathrm{c}$ & $30,6 \mathrm{c}$ & $16,6 \mathrm{~d}$ & $14,0 \mathrm{a}$ & $3,2 \mathrm{~b}$ & $2,5 \mathrm{~b}$ & 89 \\
\hline 'Fepagro C 13' & $5,2 \mathrm{~b}$ & $4,8 \mathrm{c}$ & $52,8 \mathrm{c}$ & $24,2 \mathrm{~d}$ & $19,2 \mathrm{c}$ & $3,0 \mathrm{~b}$ & $5,0 \mathrm{a}$ & $2,2 \mathrm{~b}$ & 84 \\
\hline 'Fepagro C 37' & $6,0 \mathrm{a}$ & $5,2 \mathrm{~b}$ & $74,1 \mathrm{~b}$ & $35,0 \mathrm{~b}$ & $21,2 \mathrm{c}$ & $13,8 \mathrm{a}$ & $3,1 \mathrm{~b}$ & $2,0 \mathrm{c}$ & 92 \\
\hline 'Fepagro C 41' & $6,1 \mathrm{a}$ & $6,5 \mathrm{a}$ & $116,9 \mathrm{a}$ & $20,4 \mathrm{~d}$ & $16,8 \mathrm{~d}$ & $3,2 \mathrm{~b}$ & $2,2 \mathrm{c}$ & $1,2 \mathrm{~d}$ & 48
\end{tabular}

Médias seguidas de mesma letra na coluna nấo diferem significativamente pelo teste de Tukey ( $>0,05)$. 
boa tolerância à gomose (Souza e Lobato, 2010) e por induzir as copas altas produçôes e alto índice de eficiência produtiva em tangerineira 'Ponkan' (C. reticulata Blanco) (STENZel et al., 2003).

Neste estudo, nos híbridos 'Fepagro C 13' e 'Fepagro C 37', notaram-se os maiores números de embriōes por semente, 5,0 e 3,1 respectivamente (Tabela 4), evidenciando novamente seu potencial como porta-enxertos comerciais, pois na formação de porta-enxertos, a presença de vários embrióes na mesma semente pode dificultar a sobrevivência dos embriōes zigóticos, devido à competição entre embriáo sexual e nucelares por nutrientes, contribuindo assim para manter a uniformidades das plantas e permitindo a obtenção de plantas semelhantes à planta-matriz (RAmos et al., 2006).

Foram observadas variaçóes na taxa de poliembrionia entre os porta-enxertos, com maior taxa de poliembrionia em citrumelo 'Swingle' com $94 \%$ e a menor de 48\% em 'Fepagro C 41' (Tabela 4). Os porta-enxertos 'Fepagro C 13' e 'Fepagro C 37' tiveram bons resultados, com porcentagens de poliembrionia de $84 \%$ e $92 \%$ (Tabela 4).

\section{CONCLUSÃO}

Considerando a morfologia, a forma do limbo é orbiculada no porta-enxerto Trifoliata e elipsoide nos demais porta-enxertos avaliados. Os citranges 'Fepagro C 13' e 'Fepagro C 37' possuem grande potencial como plantas doadoras de sementes para porta-enxertos, devido à boa produção de sementes/fruto, grande número de embriôes por semente e alta taxa de poliembrionia, sendo recomendados para a diversificação dos pomares de citros caso sejam considerados bons porta-enxertos.

\section{AGRADECIMENTOS}

À CAPES (Coordenação de Aperfeiçoamento de Pessoal de Nível Superior) e ao CNPq pelas bolsas de estudos concedidas aos autores.

\section{REFERÊNCIAS}

ALEZA, P.; FROELICHER, Y.; SCHWARZ, S.; AGUSTÍ, M.; HERNÁNDEZ1, M.; JUÁREZ, J.; LURO, F.; MORILLON, R.; NAVARRO, L.; OLLITRAULT, P. Tetraploidization events by chromosome doubling of nucellar cells are frequent in apomictic citrus and are dependent on genotype and environment. Annals of Botany, v.108, p.37-50, 2011.

BALLVÉ, R.M.L.; MEDINA-FILHO, H.P.; BORDIGNON, R. Identification of reciprocal hybrids in citrus by the broadness of leaf petiole wing. Revista Brasileira de Genética, v.20, p.697-702, 1997.
CAMERON, J.W.; FROST, H.B. Genetics, breeding, and nucellar embryony. In: The citrus industry. Berkeley: University of California, 1968. v.2, p.325-370.

CHAGAS, E.A.; CAZETTA, J.O.; LEMOS, E.G.M.; PASQUAL, M.; GOES, A.; RAMOS, J.D.; PIO, R.; BARBOSA, W.; MENDONÇA, V.; AMBROSIO, L.A. Identificaçáo de híbridos de citros resistentes à mancha-marrom-de-alternária por meio de AFLP e testes de patogenicidade. Pesquisa Agropecuária Brasileira, v.42, p.975-983, 2007.

DOMINGUES, E.T.; SOUZA, V.C.; SAKURAGUI, C.M.; POMPEU JÚNIOR, J.P.; PIO, R.M.; TEÓFILO SOBRINHO, J.; SOUZA, J.P. Caracterização morfológica de tangerinas do banco de germoplasma de citros do Centro de Citricultura Sylvio Moreira/ IAC. Scientia Agricola, v.56, p.197-206, 1999.

GARCIA, M.R.; ASINS, M.J.; FORNER, J.; CARBONELL, E.A. Genetic analysis of apomixis in Citrus and Poncirus by molecular markers. Theoretical and Applied Genetics, v.99, p.511-518, 1999.

IBPGR - International Board for Plant Genetic Resources. Descriptors for Citrus. Rome, 1988. 27p.

KOEHLER-SANTOS, P.; DORNELLES, A.L.C.; FREITAS, L.B. Characterization of mandarin citrus germplasm from Southern Brazil by morphological and molecular analyses. Pesquisa Agropecuária Brasileira, v.38, p.797-806, 2003.

KOLlER, O. C. Citricultura: laranja, limão e tangerina. Porto Alegre: Editora Rigel, 1994. 446p.

MOREIRA, R.A.; RAMOS, J.D.; CRUZ, M.C.M. Caracterização de frutos e poliembrionia em sementes de 'Flying Dragon' e de híbridos de porta-enxerto de citros. Revista Brasileira de Fruticultura, v.32, p.486-492, 2010.

MOURÃO-FILHO, F.A.A.; PIO, R.; MENDES, B.M.J.; AZEVEDO, F.A.; SCHINOR, E.H.; ENTELMANN, F.A.; ALVES, A.S.R.; CANTUARIAS-AVILES, T.E. Evaluation of citrus somatic hybrids for tolerance to Phytophthora nicotianae and citrus tristeza vírus. Scientia Horticulturae, v.115, p.301-308, 2008.

OLIVEIRA, R.P.; SCIVITTARO, W.B.; RADMANN, E.B. Escarificação química da semente para favorecer a emergência e o crescimento do porta-enxerto Trifoliata. Pesquisa Agropecuária Brasileira, v.41, p.1429-1433, 2006.

PASSOS, O.S.; PEIXOUTO, L.S.; SANTOS, L.C.; CORREAA CALDAS, R.C.; SOARES FILHO, W.S. Caracterização de híbridos de Poncirus trifoliata e de outros porta-enxertos de citros no Estado da Bahia. Revista Brasileira de Fruticultura, v.28, p.410-413, 2006.

POMPEU JUNIOR, J.; BLUMER, S. Híbridos de Trifoliata como porta-enxertos para a laranjeira Valência. Pesquisa Agropecuária Brasileira, v.44, p.701-705, 2009.

POMPEU JUNIOR, J.; LARANJEIRA, F.F.; BLUMER, S. Laranjeiras 'valência' enxertadas em híbridos de trifoliata. Scientia Agricola, v.59, p.93-97, 2002.

RAMOS, J.D.; ARAÚJO NETO, S.E.; CASTRO, N.E.A.; MARTINS, P.C.C.; CORREIA, M.G. Poliembrionia e caracterização de frutos de citrumelo 'Swingle' e de Poncirus trifoliata. Ciência e Agrotecnologia, v.30, p.88-91, 2006. 
SAS Institute, Inc. 2000. SAS OnlineDoc, Version 8.02. http:// v8doc.sas.com/sashtml/.

SCHÄFER, G.; BASTIANEL, M.; DORNELlES, A. L. C. Porta-enxertos utilizados na citricultura. Ciência Rural, v.31, p.723-733, 2001

SOARES FILHO, W.S.; MOREIRA, C.S.; CUNHA, M.A.P.; PASSOS, O.S. Poliembrionia e freqüência de híbridos em citrus ssp. Pesquisa Agropecuária Brasileira, v.35, p.857-864, 2000.

SOUZA, E.L.S.; LOBATO, S.M.C. Fepagro Fruticultura Taquari: memórias 80 anos. Porto Alegre: Fepagro, 2010. 67p.
STENZEL, N.M.C.; NEVES, C.S.V.J.; GOMES, J.C.; MEDINA, C.C. Performance of 'Ponkan' mandarin on seven rootstocks in southern Brazil. Hortscience, v.38, p.176-178, 2003.

STUCHI, E.S.; SEMPIONATO, O.R.; SILVA, J.A.A. Influência dos porta-enxertos na qualidade dos frutos cítricos. Laranja, v.1, p.159-178, 1996.

WEILER, R.L.; BRUGNARA, E.C.; GUERRA, D.; SCHIFINOWITTMANN, M.T.; SCHWARZ, S.F. Caracterização morfológica, determinação do nível de ploidia e viabilidade do pólen de uma progênie de tangerineira 'Clementina fina' e 'Montenegrina'. Bragantia, v.70, p.502-511, 2011. 